\title{
TRENDS IN RAPID PROTOTYPING AND SMART ENGINEERING FOR CENTRAL EUROPE BASED ON THE 3DCENTRAL PROJECT
}

doi: 10.2478/cqpi-2019-0049

Date of submission of the article to the Editor: 01/04/2019

Date of acceptance of the article by the Editor: 28/05/2019

Dariusz Karpisz ${ }^{1}$ - orcid id: 0000-0003-0848-6124

Anna Kiełbus ${ }^{1}$ - orcid id: 0000-0001-9642-6142

Johannes Brunner ${ }^{2}$

${ }^{1}$ Cracow University of Technology, Faculty of Mechanical Engineering, Jana Pawla II 37, Cracow, Poland

${ }^{2}$ IDM Südtirol - Alto Adige, Via Siemens 19, I-39100 Bolzano, Italy

Abstract: The article presents the main trends in Rapid Prototyping and Smart Engineering. The potential of Central European regions was demonstrated and characterized on the mentioned basis of which e-learning trainings were developed. Based on the implemented international project "3DCentral - Catalyzing Smart Engineering and Rapid Prototyping", selected conclusions from the implementation of the training program are presented.

Keywords: rapid prototyping, smart engineering, 3DCentral, industry 4.0

\section{INTRODUCTION}

The Interreg Central Europe Program concerns cooperation across national borders in Central Europe to make cities and regions a better place to live and work. It strengthens territorial cohesion, promotes internal integration and improves the competitiveness of Central Europe. This transnational cooperation, which is the catalyst for the implementation of intelligent solutions, is a response to regional challenges in the areas of innovation, low-carbon economy, environment, culture and transport. As a part of this Program is project entitled "3DCENTRAL - Catalysing Smart Engineering and Rapid Prototyping" (acronym: 3DCentral).

The main assumption of the 3DCentral project was to create a cooperation network of innovation regions operating in the field of intelligent engineering technology and rapid prototyping through the so-called Knowledge Axes of Central Europe (KACE) shown in Fig.1. As a part of the project, a platform for the exchange of knowledge and experience between research and industrial centers in the field of intelligent engineering and rapid prototyping was built. Various actions were taken to aimed at strengthening the links between the participants of innovation systems (through transnational cooperation), leading to increasing the innovation potential of the Central European regions. 
The 3DCentral project focused Project Partners who represent technology hubs and specialist knowledge in Central Europe. The partners are representatives of selected regions from Italy, Austria, Germany, Slovenia, Hungary and Poland. All of these partners have an extensive network of organizations as research institutions, companies, clusters, who carry knowledge and expertise related to smart engineering and rapid prototyping.

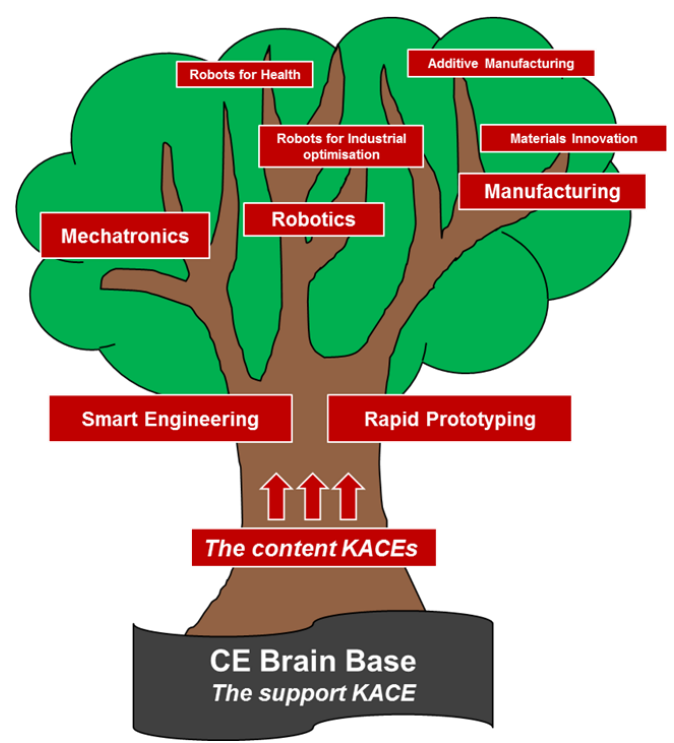

Fig. 1. The concept of Knowledge Axis (KACE) in the 3DCentral project (source: (Work Package T1, 2016))

\section{METHODS}

The project actions have been taken to provide a specialized support program - a network of cooperation between regions. Good practices associated with rapid prototyping and smart engineering have been gathered in the regions.

All the good practices and associated lessons learnt are derived from real-life examples to which the Project Partner has been exposed. The methodology behind is composed of two major steps:

- 1st step - identification of Smart Engineering \& Rapid Prototyping solutions offered by SMEs and research institutions in each region.

- 2nd step - out of identified regional solution providers Good Practices and Lessons Learnt were selected and described by each partner (Deliverable D.T1.1.1, 2018).

On this basis, the Axes of Knowledge of Central Europe, i.e.:

1) Additive manufacturing, 3D Design / Engineering / Scanning; 2) Smart and functional materials; 3) Digital life; 4) Technologies for sustainable manufacturing; 5)Virtual and augmented reality for manufacturing; 6) Value-added virtual supply chains; 7) Smart services; 8) Robotics; 9) Mechatronics.

A diversity of different practices related to smart engineering \& rapid prototyping in different technologies and cross sectors - from development of smart services to the optimization of entire production processes - led to identification of 10 specialized topics which served as a base for a road-map and action plans development. The action plans were a solid basis for joint activities such as R\&D projects that form the basis for capitalization, training in the Moodle e-learning platform format and strategic activities in the form of workshops with key stakeholders. 
As part of the activities carried out in the project, the Knowledge Innovation Technology Transfer Scouts (KITTS) program was developed. As part of the activities carried out in the project, the Knowledge Innovation Technology Transfer Scouts (KITTS) programme was developed.

This act ensuring continuity of activities between "Actions Transnational Hub for Common Knowledge and Knowledge Databases" with them, pilot and demonstration activities undertaken in "Practice Transnational Hub for Pilot Cases and Capitalisation".

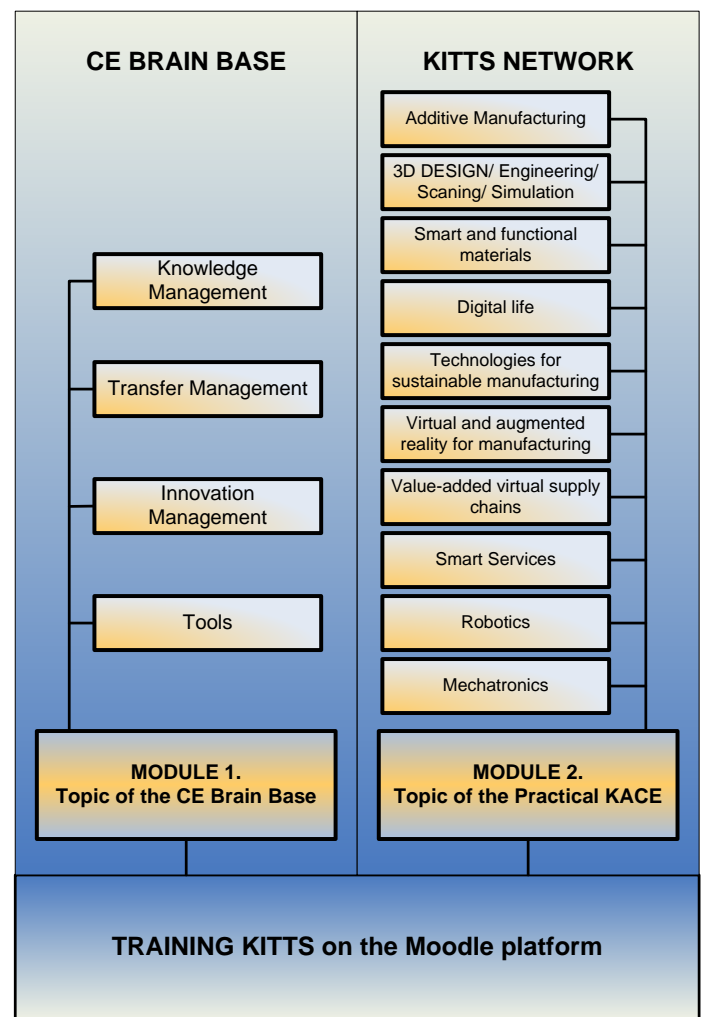

Fig. 2. The KITTS curriculum (source: (Deliverable D.T2.3.4, 2018))

The curriculum content for KITTS should utilize information generated from the best practices and lessons learnt and should help in building up a strategic system for transnational knowledge axis. Therefore, the implementation plan for KITTS needs to take advantage of the meetings/workshops, along with mobility actions ("Transnational hub for change elements"), to ensure executing wider work packages.

In such case as mentioned above, the KITTS curriculum consists of 14 themes divided into 2 modules (Fig. 2).

The first module of training KITTS package was the CE Brain Base, consisting of 4 subtopics (Deliverable D.T.2.3.1, 2016): knowledge management (Jashapara, 2010), transfer management (Ouma-Onyango, 2018), innovation management (Goffin and Mitchell, 2016), and tools.

Those four topics are prioritized within the KITTS Curriculum in the first stage of the training, because they are considered as the base pillars, which are essential for understanding knowledge, innovation technology transfer, the appropriate methodologies and tools, which can be used to facilitate the knowledge transfer. These subjects support the main topics related to the development and repeatability, dissemination and implementation of transfer and innovative activities, KACE 
development and related tasks that had to be completed to fill in the effective transfer of innovation.

The second module, the Practical KACES, consists of 10 different topics, which are more practically oriented, depending on the interests of KITTS (for developed course topics with the partners responsible for their creation shown table 1). Each of the partners co-create at least two courses (as KACE Leader or KACE support).

Table 1

Practical KACEs (Delierable D.T2.3.1, 2016)

\begin{tabular}{|l|c|c|}
\hline \multicolumn{1}{|c|}{ KACE name } & \multicolumn{1}{|c|}{$\begin{array}{c}\text { Proposed } \\
\text { KACE leader }\end{array}$} & $\begin{array}{c}\text { Proposed } \\
\text { KACE support }\end{array}$ \\
\hline 1. Additive manufacturing & PK & IWU \\
\hline $\begin{array}{l}\text { 2. 3D Design / Engineering / Scanning / } \\
\text { Simulation }\end{array}$ & IDM & PBN \\
\hline 3. Smart and functional materials & IWU & EVO \\
\hline 4. Digital life & TPLj & TPLj \\
\hline $\begin{array}{l}\text { 5. Technologies for sustainable } \\
\text { manufacturing }\end{array}$ & AFIL & AFIL \\
\hline $\begin{array}{l}\text { 6. Virtual and augmented reality for } \\
\text { manufacturing }\end{array}$ & WRS & CAM \\
\hline 7. Value-added virtual supply chains & PTP & WRS \\
\hline 8. Smart Services & PBN & PTP \\
\hline $\begin{array}{l}\text { 9. Robotics (components, machines } \\
\text { and intelligent robots) }\end{array}$ & KPT & \\
\hline $\begin{array}{l}\text { 10. Mechatronics (sensor, monitoring } \\
\text { and control) }\end{array}$ & CAM & \\
\hline
\end{tabular}

For the KITTS training on the selected topics, to do four different modules, which are mainly done in the e-learning environment Moodle was decided. Choice of integrate elearning it is flexible when issues of time and place are taken into consideration. So every Partner/KITTS has the luxury of choosing the place and time. Additionally elearning enhances availability of knowledge and qualifications because of the easy access to information.

\section{RESULTS}

As part of the project, training in rapid prototyping and smart engineering was developed on the 3DCENTRAL platform and divided into methodological and thematic types. The start window of the courses WWW platform is shown in Figure 3.

Each of ten thematic courses was dedicated to specific technology, ie: additive production, 3D design, engineering, scanning and simulation, intelligent and functional materials, digital life, technologies for sustainable production, virtual and augmented reality for production, virtual value added supply chains, intelligent services, robotics (components, machines and intelligent robots), mechatronics (sensor, monitoring and control). All thematic courses have focused on trends and practical aspects.

Each course resembles an interactive textbook, with pre-recorded videos, quizzes, and project description. Student is guided through the whole course and can discuss further subjects or critical issues with the teacher at any time. The content and duration of the courses may differ, yet they are all designed to share information at the highest possible 
level. The platform also offers an event calendar, where the student can plan and monitor own activity and the progress of self-development.

Until June 2017, 33 KITTS participants were recruited for use of the CE BrainBase courses (Knowledge Management, Transfer Management, Innovation Management) in the 3DCentral platform. For the end of June 2018, users created accounts on the 3DCentral platform, of which 273 completed selected on-line courses. Among the thematic courses, the greatest interest and activity of users was enjoyed by the course Additive Manufacturing (191 users), 3DDesign / Engineering / Scaning (95 users), Robotic (95 users), Digital Life (89 users). Graph 1 presents the number of people trained on the 3DCentral platform.

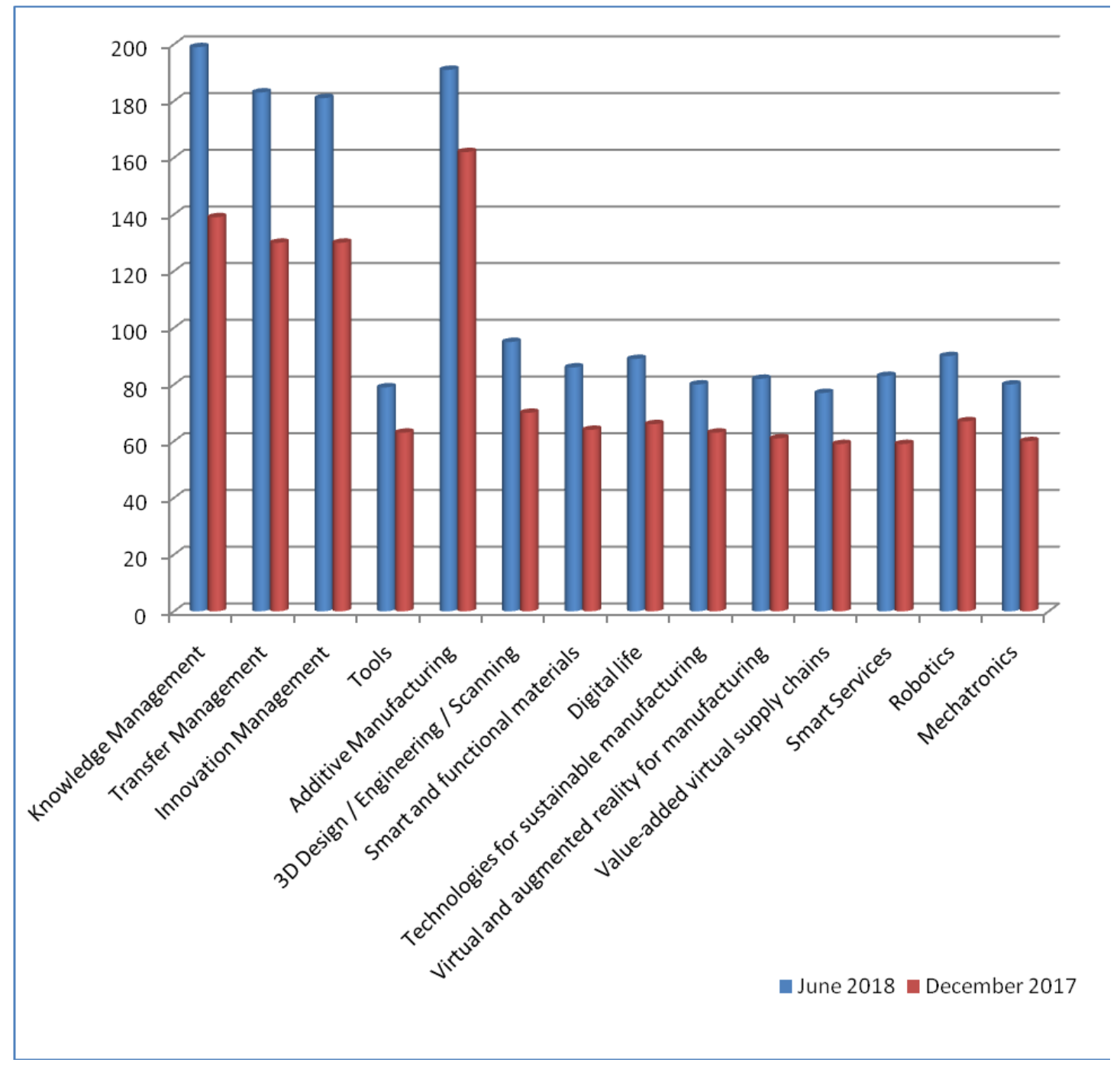

Fig. 3. Number of people trained on the 3DCENTRAL platform, by type of courses (source: (Deliverable D.T2.3.3, 2018))

The 3D Central platform encourages discussion, and critical and reflective thinking. It also fosters the exchange of ideas and thoughts, providing opportunities for establishing relations and sharing information within its members. It became a window to share knowledge and acquire new skills, and above all was a stimulus to build cooperation networks and joint pilot activities. Idea behind the 3DCentral concept was to identify possibilities which could be transferred via pilot actions to various industries 
and also in later stages as follow up projects. Following lessons learned, a total of 11 flagship projects and 22 Transfer and Cooperation Actions were initiated during the project duration and realized beyond the end of the project. The flagship projects, transfer and cooperation actions served directly the overall project goal to connect islands of innovation related to smart engineering and rapid prototyping in Central Europe.

\section{DISCUSSION}

The transfer of scientific achievements is an inseparable element of global reality, including business (Kozien, 2017) and even juridical and political relations. Among the main reasons of such tendency is the increasing cooperation of $R \& D$ centers with entities implementing modern solutions in practice and popularizing access to scientific works, being the foundation of the implemented concepts.

By observing the modern economy, and in particular the growing demands on employees regarding their competences, knowledge and attitudes, it is not difficult to notice that a gap is growing, when comparing the mentioned requirements with the offer of the university or scientific units. Traditional universities are not able to meet these all requirements (Kozien and Kozien, 2017). The aspiration of people for continuous learning, development, improving their own qualifications, allow them to work more efficiently and more effectively in a specific environment, increasing the demand for knowledge, specific to a given business.

Organizations build their competitive advantage based on non-material factors: knowledge, reputation, values, ethics. This specific set, that distinguishes the organization from a number of others, must be constantly modeled and strengthened. Cooperation and transfer of knowledge is therefore important, that should be looked into by both industry specialists and researchers. After analyzing the completed 3DCentral project, it can be concluded that: the most important achievement of the partnership was that we managed to demonstrate cross-sectoral characteristic. It shows that advanced manufacturing techniques such as smart engineering and rapid prototyping, are relevant and currently in practice across different aspects of Central Europe's value-chain. It also shows that techniques can be applied across many sectors, e.g. some new solutions that emerges in the municipal transportation sector, could be viable in the industrial engineering sector or new fabric that is viable in the textile industry, could be applied in the medical sector.

The considerations and results presented in this paper ay be very useful for researchers in any scientific area, especially in applied sciences e.g. biotechnology (SkrzypczakPietraszek et al., 2018), materials science (Lipinski, 2010; Szczotok et al., 2018), machining (Ulewicz and Selejdak, 2018), special coating (Pliszka et al., 2018; Radek et al., 2018a; Radek et al., 2018b) or machine building (Pacana and Pacana, 2018), especially heavy-duty (Domagala et al., 2018a; Domagala et al., 2018b; FabisDomagala et al., 2018) where safety is critical issue. Mutual checking of proposed models is important in rapidly developing scientific area known as "surrogate models": creation of simpler model derived from more complex, but also numerically simulated (Gadek-Moszczak et al., 2015; Pietraszek et al., 2016; Filo et al., 2018; Osocha, 2018). Communication and knowledge dissemination are also important for industry e.g. transfer of specific scientific knowledge to create anti-graffitti protective coating for trains (Pasieczynski et al., 2018). 
Anyway, there is no doubt that the exchange of scientific information and cooperation of teams are crucial for the further development of academic activities at universities.

\section{REFERENCES}

Deliverable D.T1.1.1, 2018. Report on knowledge, transfer and case management for the project core group and their stakeholders. 3DCentral project documentation.

Deliverable D.T2.3.1, 2016. Curriculum \& recruiting scheme for KITTS - Knowledge Innovation Technology Transfer Scouts network. 3DCentral project documentation.

Deliverable D.T2.3.3, 2018. Report On KITTS Network. 3DCentral project documentation.

Deliverable D.T2.3.4, 2018. Report on CE Brain Base. 3DCentral project documentation.

Domagala, M., Momeni, H., Domagala-Fabis, J., Filo, G., Krawczyk, M., 2018a. Simulation of Cavitation Erosion in a Hydraulic Valve. Materials Research Proceedings, 5, 1-6. DOI: 10.21741/9781945291814-1

Domagala, M., Momeni, H., Domagala-Fabis, J., Filo, G., Kwiatkowski, D., 2018b. Simulation of Particle Erosion in a Hydraulic Valve. Materials Research Proceedings, 5, 17-24. DOI: 10.21741/9781945291814-4

Fabis-Domagala, J., Filo, G., Momeni, H., Domagala, M., 2018. Instruments of identification of hydraulic components potential failures. MATEC Web Conf., 183, art. 03008. DOI: $10.1051 /$ matecconf/201818303008

Filo, G., Lisowski, E., Domagala, M., Fabis-Domagala, J., Momeni, H., 2018. Modelling of pressure pulse generator with the use of a flow control valve and a fuzzy logic controller. AIP Conf. Proc., 2029, art. 020015. DOI: 10.1063/1.5066477

Gadek-Moszczak, A., Radek, N., Wronski, S., Tarasiuk, J., 2014. Application the 3D image analysis techniques for assessment the quality of material surface layer before and after laser treatment. Adv. Mat. Res. Switz., 874, 133-138. DOI: 10.4028/www.scientific.net/AMR.874.133

Goffin K., Mitchell R., 2016. Innovation Management: Efective strategy \& implementation. Macmillan Education, London.

Jashapara, A., 2010. Knowledge Management. Pearson Education Limited, London.

Kozien, E., 2017. Identification of stage phase growth in the checklist method using different statistical parameters. 20 ${ }^{\text {th }}$ Int. Sci. Conf. Economic and Social Development, Prague, Varazdin, 538-545.

Kozien, E., Kozien, A., 2017. Commercialization of scientific research results and transfer knowledge and technologies to economy as determinants of development of universities and enterprises in Poland - legal and economic perspective. $26^{\text {th }}$ Int. Sci. Conf. Economic and Social Development, Zagreb, Varazdin, 326-335.

Lipinski, T., 2010. The structure and mechanical properties of Al-7\%SiMg alloy treated with a homogeneous modifier. Solid State Phenomena, 163, 183-186. DOI: 10.4028/www.scientific.net/SSP.163.183

Osocha, P., 2018. Calculation of Residual Life for P91 Material Based on Creep Rate and Time to Rupture. Materials Research Proceedings, 5, 177-182. DOI: 10.21741/9781945291814-31

Ouma-Onyango, R., 2018. Information resources and technology transfer management in developing countries. Routledge Library Editions. 
Pacana, J., Pacana, A., 2018. Analysis of Possibilities of Using Polymeric Materials for Testing Prototypes of Harmonic Drive. Materials Research Proceedings, 5, 61-66. DOI: $10.21741 / 9781945291814-11$

Pasieczynski, L., Radek, N., Klonica, M., Kaminski, J., Swiderski, J., 2018. Properties of BO100-AGR Clearcoat Anti-Graffiti Coating Systems used in the Railway Industry. Materials Research Proceedings, 5, 225-230. DOI: 10.21741/9781945291814-40

Pietraszek, J., Kolomycki, M., Szczotok, A., Dwornicka, R., 2016. The fuzzy approach to assessment of ANOVA results. ICCCI 2016: Conf. on Comp. Collective Intell. Springer, 260-268. DOI: 10.1007/978-3-319-45243-2_24

Pliszka, I., Radek, N., Gadek-Moszczak, A., Fabian, P., Paraska, O., 2018. Surface Improvement by WC-Cu Electro-Spark Coatings with Laser Modification. Materials Research Proceedings, 5, 237-242. DOI: 10.21741/9781945291814-42

Radek, N., Pietraszek, J., Szczotok, A., 2018a. Microstructure and Tribological Properties of ESD Coatings after Laser Processing. Materials Research Proceedings, 5, 206-209. DOI: 10.21741/9781945291814-36

Radek, N., Szczotok, A., Gadek-Moszczak, A., Dwornicka, R., Broncek, J., Pietraszek, J., 2018b. The impact of laser processing parameters on the properties of electrospark deposited coatings. Arch. Metall. Mater., 63, 809-816. DOI: 10.24425/122407

Skrzypczak-Pietraszek, E., Reiss, K., Zmudzki, P., Pietraszek, J., 2018. Enhanced accumulation of harpagide and 8-O-acetyl-harpagide in Melittis melissophyllum L. agitated shoot cultures analyzed by UPLC-MS/MS. PLoS ONE 2018, 13, art. e0202556. DOI: 10.1371/journal.pone.020255610.1371/journal.pone.0202556

Szczotok, A., Radek, N., Dwornicka, R., 2018. Effect of the induction hardening on microstructures of the selected steels. METAL 2018: 27th Int. Conf. Metallurgy and Materials. Ostrava, Tanger, 1264-1269.

Ulewicz, R., Selejdak, R., 2018. Impact of Laser Machining on the Structure and Properties of Tool Steels. Materials Research Proceeding, 5, 37-40. DOI: 10.21741/9781945291814-7

Work Package T1, 2016. BUILD! Transnational hub for common knowledge. MINDCONSULT, 3DCentral project documentation. 